\title{
Editor-in-Chief Introduction and Welcome
}

\author{
Lydia M. Hopper \\ Department of Molecular and Comparative Pathobiology, Johns Hopkins University School of Medicine \\ Email: lhopper7@jhmi.edu (iD) https://orcid.org/0000-0001-5953-3264
}

Citation - Hopper, L. M. (2022). Editor-in-Chief introduction and welcome. Animal Behavior and Cognition, 9(1), 1-2. https://doi.org/10.26451/abc.09.01.01.2022

In January 2022, I started my appointment as the new Editor-in-Chief for Animal Behavior and Cognition. I want to take this opportunity to introduce myself and the new editorial team and to reflect on my goals for the journal. I am extremely honored that the Editorial Board voted to elect me as Editor-inChief and I am thankful to the journal's former co-Editors, Dr. Jennifer Vonk and Dr. Mike Beran, who have expertly stewarded the journal since 2016, and who facilitated a smooth transition for me as I took on this role. Under their leadership, the reputation and success of this journal has increased, and I am committed to ensuring the continued growth of this journal during my tenure as Editor-in-Chief. Happily, both Drs. Beran and Vonk will remain engaged with the journal as Associate Editors, and are joined by Dr. Jason Bruck, Dr. Sarah-Elizabeth Byosiere, and Dr. Christian Nawroth as part of our newly formed team of Associate Editors. This represents a new editorial structure for the journal, but one that I believe will increase its rigor. Importantly, the wide-ranging research interests and specialisms of the Associate Editors reflects the multi-disciplinary nature of this journal and the scholarly work that we publish.

My own research focuses on primate social cognition, which I examine via a comparative approach to best understand the underlying mechanisms and functions of observed behaviors. Indeed, the scope of my research is reflected among the articles that I have published in this very journal (Bernstein-Kurtycz et al., 2020; Cronin et al., 2018; Huskisson et al., 2021). Throughout my career, I have been fortunate to work in a variety of settings, including zoos, sanctuaries, and research facilities, applying different tools and technologies to address questions about animal behavior, cognition, and welfare. I am also passionate about research method development and refinement in order to enhance research validity and captive animal wellbeing.

Given my varied research interests, I am excited to be Editor-in-Chief for a multi-disciplinary journal that publishes articles covering an array of species, topics, and methods. Moreover, I am especially proud to support Animal Behavior and Cognition given its open access publication model that ensures it is free both to publish and to read accepted articles. Increasing accessibility is fundamental to diversifying scientific practice and removing article processing charges goes some way to achieving this. Furthermore, open access science fosters public engagement with, and trust in, research, via a transparent and unrestricted reporting process for peer-reviewed research.

This journal was founded by Dr. Stan Kuczaj (Vonk et al., 2016), who published the first issue of Animal Behavior and Cognition in February 2014. Since that first issue, we have continued to publish four issues a year, which have shared articles on a broad range of topics related to animal behavior, cognition, and welfare. The success of this journal relies on the dedicated support of a team of people including our Associate Editors, the members of our Editorial Board, and our Copy Editing team, all of whom volunteer their time and expertise to ensure the integrity of this journal. I want to thank them, and to recognize the 
work of Dr. Mark Krause who oversaw the copy editing and production of our published articles for many years. At the end of last year, he stepped down and was superseded by Kevin Leonard, our newly appointed Senior Copy Editor, who works with Drs. Holli Eskelinen, Pepper Hanna, and Lauren Miller to copy edit proofs and format articles for publication.

Animal Behavior and Cognition accepts a number of different article formats, including research reports, replication reports, review articles, opposing viewpoint articles, and pre-registered reports. Given the array of topics and article formats that we accept, we encourage you to consider submitting your next article to this journal. We also welcome proposals for special issues and would be especially interested in presenting work related to companion animals, farm animals, and applied ethology. Please submit articles and proposals for special issues to animalbehaviorandcognition@gmail.com for consideration by the editorial team.

\section{References}

Cronin, K.A., Bethell, E.J., Jacobson, S.J., Egelkamp, C., Hopper, L.M., \& Ross, S.R. (2018). Evaluating mood changes in response to anthropogenic noise with a response-slowing task in three species of zoo-housed primates. Animal Behavior and Cognition, 5(2), 209-221.

Bernstein-Kurtycz, L.M., Hopper, L.M., Ross, S.R., \& Tennie, C. (2020). Zoo-housed chimpanzees can spontaneously use tool sets but perseverate on previously successful tool-use methods. Animal Behavior and Cognition, 7(3), 288-309.

Huskisson, S.M., Egelkamp, C.L., Jacobson, S.L., Ross, S.R., \& Hopper, L.M. (2021). Primates' food preferences predict their food choices even under uncertain conditions. Animal Behavior and Cognition, 8(1), 69-96.

Vonk, J., Beran, M., \& Hill, H. (2016). Reflections: Students' tribute to Stan Kuczaj (1950-2016). Animal Behavior and Cognition, 3(3), 120-130. 